\title{
Evaluation of mandibular length in subjects with Class I and Class II skeletal patterns using the cervical vertebrae maturation
}

\section{Rodrigo Generoso(a) Elaine Cristina Sadoco ${ }^{(b)}$ Mônica Costa Armond(c) Gustavo Hauber Gameiro(d)}

\footnotetext{
(a) Professor; (b) MSc in Orthodontics - Department of Orthodontics, School of Dentistry, Vale do Rio Verde University, Três Corações, MG, Brazil.

(c) Professor, Department of Oral Diagnosis, School of Dentistry, Vale do Rio Verde University, Três Corações, MG, Brazil.

(d) Professor, Department of Physiology, Federal University of Rio Grande do Sul, Porto Alegre, RS, Brazil.
}

\begin{abstract}
The aim of this study was to compare the mandibular size in boys and girls with Class I and Class II skeletal patterns, taking into consideration the bone maturation stage, as defined by the cervical vertebrae maturation. One hundred and sixty cephalometric radiographs were obtained from subjects (aged between 7 and 12 years) with Class I or Class II skeletal patterns, according to the ANB angle and WITS appraisal. The Class I sample consisted of 80 subjects (40 boys, 40 girls). The Class II sample also consisted of 80 subjects ( 40 boys, 40 girls). On a cross-sectional basis, mandibular length (Co-Gn) was compared between groups and genders. The between-stages changes were also evaluated, with the cervical vertebrae analysis used for establishing the bone maturation stages at CS2, CS3, CS4 and CS5. The results were statistically analyzed by the Kruskal-Wallis test. The mandibular length differed between skeletal patterns only at the earlier stages of development. In the Class I pattern, the mandibular lengths of boys were greater than those of girls at stages CS2, CS4 and CS5, whereas in the Class II pattern, the mandibular lengths of boys were greater than those of girls at stages CS2, CS3 and CS4. The present results indicate a sexual dimorphism in the mandibular length at almost all stages of bone maturation, in exception of the CS5 stage in Class II.
\end{abstract}

Descriptors: Mandible; Cervical vertebrae; Growth and development.

\section{Introduction}

The optimal timing to take advantage of bone remodeling for correcting skeletal discrepancies, often involved in the development of malocclusions, depends on the identification of periods of accelerated or intense growth that can contribute significantly to the correction of these problems in a patient. ${ }^{1}$ The classical and most widely used method for skeletal-age evaluation is the highly reliable hand-wrist bone analysis performed by radiograph. ${ }^{2}$ However, this analysis implies extra radiation exposure for the patients. Currently, the cervical vertebrae investigation method has been increasing, since it avoids further exposure to ionizing radiation in addition to the routine radiographic records required for an orthodontic treatment. ${ }^{3-7}$ This method has proved effective in assessing the adolescent growth peak both in body height and mandibular size., 
Moreover, almost all studies found statistically significant correlations between hand-wrist and skeletal maturation of the cervical vertebrae, ${ }^{4,9-12}$ but racial variations in these relationships were also reported..$^{10,11}$

Class II malocclusion is a commonly observed clinical problem, occurring in about a quarter of the young Brazilian population ${ }^{13}$ and in up to a third of the United States population. ${ }^{14}$ Despite the substantial prevalence of Class II malocclusion as an orthodontic problem, review of the related literature showed no consensus with regard to the growth changes of the mandible in untreated subjects with Class II malocclusion, when compared with subjects with normal occlusion. Some studies reported that subjects with Class II malocclusion had shorter mandibles at both infantile and adolescent ages. ${ }^{15-18}$ In contrast, others ${ }^{19,20}$ found no differences in mandibular growth in Class II subjects from the deciduous dentition through the permanent dentition. However, the results in most of these studies were based on longitudinal growth changes related to the subjects' chronologic ages or the dentition stages, which according to many authors, are not reliable predictors of a patient's stage of skeletal development. ${ }^{7,9,21-23}$

To our knowledge, only one study compared the craniofacial dimensions in subjects with normal occlusion and Class II malocclusion, considering the cervical vertebrae method as a biological indicator of individual skeletal maturity to analyze the results. ${ }^{24}$ These authors showed that subjects with Class II malocclusion had smaller increases in mandibular length at the growth spurt, and this dentoskeletal disharmony did not tend to self-correct with growth. However, the possible differences in the mandibular size according to gender were not investigated in this study.

On this background, the aim of the present study was to compare mandibular size and cervical vertebrae maturation in subjects of both genders with Class I and Class II malocclusions.

\section{Materials and Methods}

The total sample (160 cephalometric radiographs) was obtained at the Orthodontic Department, School of Dentistry, Vale do Rio Verde Uni- versity (UNINCOR). This study was designed as a cross-sectional research project. All the participants were aged between 7 and 12 years with no orthodontic treatment at the time of study. They were divided in Class I or Class II skeletal patterns, according to the ANB angle and WITS appraisal. Class II subjects had the ANB angle greater than $4^{\circ}$ and the linear distance between AO and BO (WITS appraisal) greater than $1 \mathrm{~mm}$. They also presented an overjet greater than $2.5 \mathrm{~mm}$. Class I subjects had the ANB angle between 0 and $3^{\circ}$, with normal distances between $\mathrm{AO}$ and $\mathrm{BO}(-1$ to $1 \mathrm{~mm})$. The Class I sample consisted of 80 subjects ( 40 boys, 40 girls). The Class II sample also consisted of 80 subjects (40 boys, 40 girls). This study was approved by the research ethics committee of UNINCOR.

Cervical vertebrae stages were determined by the Hassel and Farman ${ }^{4}$ (1995) modification of the criteria of Lamparski ${ }^{25}$ (1972), which established the 6 maturational stages by the observation of the bodies of the second, third, and fourth cervical vertebrae (Table 1).

Table 1 - Six stages in the evaluation of cervical vertebrae maturation according to the method of Hassel and Farman.

\begin{tabular}{|c|c|}
\hline Stage & Description \\
\hline $\begin{array}{c}1 \\
\text { (initiation) }\end{array}$ & $\begin{array}{l}\text { Vertebrae are wedge-shaped, with superior } \\
\text { vertebral borders tapering from posterior to } \\
\text { anterior; inferior borders of bodies of all cervical } \\
\text { vertebrae are flat }\end{array}$ \\
\hline $\begin{array}{c}2 \\
\text { (acceleration) }\end{array}$ & $\begin{array}{l}\text { Concavities develop on inferior borders of } \\
\mathrm{C} 2 \text { and } \mathrm{C} 3 \text {; bodies of } \mathrm{C} 3 \text { and } \mathrm{C} 4 \text { are nearly } \\
\text { rectangular, and inferior border of C } 4 \text { is flat; } \\
\text { anterior vertical height of bodies increases }\end{array}$ \\
\hline $\begin{array}{c}3 \\
\text { (transition) }\end{array}$ & $\begin{array}{l}\text { Distinct concavities develop on inferior borders } \\
\text { of } C 2 \text { and } C 3 \text {; concavity begins to develop on } \\
\text { inferior border of } C 4 \text {, and bodies of } C 3 \text { and } C 4 \\
\text { are rectangular }\end{array}$ \\
\hline $\begin{array}{c}4 \\
\text { (deceleration) }\end{array}$ & $\begin{array}{l}\text { Clear concavities are seen on inferior borders } \\
\text { of C2, C } 3 \text {, and C } 4 \text { with bodies of C } 3 \text { and C } 4 \\
\text { nearly square; bodies of all cervical vertebrae } \\
\text { are rectangular }\end{array}$ \\
\hline $\begin{array}{c}5 \\
\text { (maturation) }\end{array}$ & $\begin{array}{l}\text { Accentuated cavities are seen on inferior borders } \\
\text { of C2, C3, and C4, and bodies of C } 3 \text { and C } 4 \\
\text { are nearly square; concavities are well defined in } \\
\text { lower borders of bodies of all cervical vertebrae; } \\
\text { spaces between bodies are reduced }\end{array}$ \\
\hline $\begin{array}{c}6 \\
\text { (completion) }\end{array}$ & $\begin{array}{l}\text { Deep concavities are seen on inferior borders of } \\
\mathrm{C} 2, \mathrm{C} 3 \text {, and } \mathrm{C} 4 \text {, and vertebral bodies are more } \\
\text { vertical than horizontal }\end{array}$ \\
\hline
\end{tabular}


The stages CS2, CS3, CS4 and CS5, in which significant skeletal growth occurs, were used in the present study to divide the sample according to their skeletal stage (Table 2).

Total mandibular length (Co-Gn) was measured on cephalograms traced by 1 investigator and verified for landmark location and anatomical contours by another. Any disagreements were resolved by retracing the landmark or structure to the satisfaction of both observers. The measurements were performed manually in a blinded manner, and Dahlberg's formula was used to calculate the intra-operator error, by re-counting 10 randomly selected radiographs fifteen days later. The formula revealed values below 1.0, indicating sufficient accuracy of the measurements.

All assessments were performed in a darkened room with a radiographic illuminator to ensure contrast enhancement of the bone images.

Table 2 - Sample distribution in relation to bone maturation stage in subjects with Class I and Class II skeletal patterns.

\begin{tabular}{c|c|c}
\hline \multirow{2}{*}{$\begin{array}{c}\text { Bone maturation } \\
\text { stage }\end{array}$} & \multicolumn{2}{|c}{ Groups according to skeletal pattern } \\
\cline { 2 - 3 } CS2 & Class I & Class II \\
\hline \multirow{2}{*}{ CS3 } & $\begin{array}{c}\text { Male }(n=10) \\
\text { Female }(n=10)\end{array}$ & $\begin{array}{c}\text { Male }(n=10) \\
\text { Female }(n=10)\end{array}$ \\
\hline CS4 & Male $(n=10)$ & Male $(n=10)$ \\
& Female $(n=10)$ & Female $(n=10)$ \\
\hline CS5 & Male $(n=10)$ & Male $(n=10)$ \\
& Female $(n=10)$ & Female $(n=10)$ \\
\hline \multirow{2}{*}{ Male $(n=10)$} & Male $(n=10)$ \\
Female $(n=10)$ & Female $(n=10)$ \\
\hline
\end{tabular}

Descriptive statistics were obtained for total mandibular length in both Class I and Class II samples at the different maturation stages. Because of the small subsample sizes, the Kruskal-Wallis test was used to compare the mandibular lengths in the following situations: (1) Class II vs. Class I samples at CS2, CS3, CS4 and CS5 (2) male vs. female in each sample and (3) between-stage changes (CS2CS3, CS3-CS4, CS4-CS5) in Class I and Class II samples. The significance level was set at $\mathrm{p}<0.05$.

\section{Results}

The total mandibular lengths (Co-Gn) in Class I and Class II subjects at the CS2, CS3, CS4 and CS5 stages are shown in Table 3. Class I boys presented greater mandibular lengths than Class II boys at stages CS2 and CS3. The differences at stages CS4 and CS5 were not statistically significant in this group. In the female group, Class I girls presented a greater mandibular length than Class II girls only at stage CS3. At the other stages, the differences were not statistically significant (Table 3).

The comparisons between genders revealed different results depending on the skeletal pattern evaluated. In the Class I pattern, the mandibular lengths of boys were greater than those of girls at stages CS2, CS4 and CS5. In the Class II pattern, the mandibular lengths of boys were greater than those of girls at stages CS2, CS3 and CS4 (Table 3).

The comparisons of between-stage changes (CS2-CS3, CS3-CS4, CS4-CS5) in Class I and Class II samples are shown separately for boys (Table 4),

\begin{tabular}{|c|c|c|c|c|}
\hline \multirow{11}{*}{$\begin{array}{r}\text { Table } 3 \text { - Mean } \pm \text { standard } \\
\text { deviation }(\mathrm{mm}) \text { of mandibular } \\
\text { length }(\mathrm{Co}-\mathrm{Gn}) \text { in subjects with } \\
\text { Class I and Class II skeletal } \\
\text { patterns in the four stages of bone } \\
\text { maturation. }\end{array}$} & & & \multicolumn{2}{|c|}{ Skeletal pattern } \\
\hline & & & Class I & Class II \\
\hline & (maturation stage) & (Gender) & \multicolumn{2}{|c|}{ (mandibular length) } \\
\hline & \multirow{2}{*}{ CS2 } & Male & $112.1 \pm 5.0^{* \#}$ & $108.6 \pm 4.3^{\#}$ \\
\hline & & Female & $103.2 \pm 3.0$ & $103.0 \pm 3.6$ \\
\hline & \multirow{2}{*}{ CS3 } & Male & $115.1 \pm 5.9^{*}$ & $110.0 \pm 3.9 *$ \\
\hline & & Female & $110.6 \pm 2.9^{*}$ & $106.1 \pm 3.3$ \\
\hline & \multirow{2}{*}{ CS4 } & Male & $122.6 \pm 5.1^{\#}$ & $121.0 \pm 5.7^{\#}$ \\
\hline & & Female & $116.2 \pm 4.0$ & $113.4 \pm 3.4$ \\
\hline & \multirow{2}{*}{ CS5 } & Male & $127.4 \pm 6.4^{\#}$ & $127.4 \pm 2.7$ \\
\hline & & Female & $118.4 \pm 3.9$ & $122.2 \pm 6.9$ \\
\hline
\end{tabular}




\begin{tabular}{|c|c|c|c|c|}
\hline Table 4 - Mean \pm standard & & & Skeletal & pattern \\
\hline $\begin{array}{l}\text { deviation ( } \mathrm{mm} \text { ) of mandibular } \\
\text { length (Co-Gn) in boys with Class }\end{array}$ & & & Class I & Class II \\
\hline | and Class II skeletal patterns & (maturation stage) & (Gender) & (mandibu & ar length) \\
\hline regarding the between-stages & CS2 & Male & $112.1 \pm 5.0$ & $108.6 \pm 4.3$ \\
\hline & CS3 & Male & $115.1 \pm 5.9$ & $110.0 \pm 3.9$ \\
\hline & CS4 & Male & $122.6 \pm 5.1$ & $121.0 \pm 5.7$ \\
\hline & CS5 & Male & $127.4 \pm 6.4$ & $127.4 \pm 2.7$ \\
\hline & $\begin{array}{r}\text { Statistical compar } \\
\text { stages ( } p\end{array}$ & $\begin{array}{l}\text { s between- } \\
\text { 05) }\end{array}$ & $(\mathrm{CS} 2=\mathrm{CS} 3)<\mathrm{CS} 4<\mathrm{CS} 5$ & $(\mathrm{CS} 2=\mathrm{CS} 3)<\mathrm{CS} 4<\mathrm{CS} 5$ \\
\hline
\end{tabular}

Table 5 - Mean \pm standard deviation $(\mathrm{mm})$ of mandibular length (Co-Gn) in girls with Class I and Class II skeletal patterns regarding the between-stages differences.

\begin{tabular}{c|c|c|c}
\hline & & \multicolumn{2}{|c}{ Skeletal pattern } \\
\hline & & Class I & Class II \\
\hline (maturation stage) & (Gender) & \multicolumn{2}{|c}{ (mandibular length) } \\
\hline CS2 & Female & $103.2 \pm 3.0$ & $103.0 \pm 3.6$ \\
\hline CS3 & Female & $110.6 \pm 2.9$ & $106.1 \pm 3.3$ \\
\hline CS4 & Female & $116.2 \pm 4.0$ & $113.4 \pm 3.4$ \\
\hline CS5 & Female & $118.4 \pm 3.9$ & $122.2 \pm 6.9$ \\
\hline $\begin{array}{c}\text { Statistical comparisons between- } \\
\text { stages }(p<0.05)\end{array}$ & $($ CS2 $=C S 3)<(C S 4=C S 5)$ & $($ CS2 $=C S 3)<C S 4<C S 5$ \\
\hline
\end{tabular}

and girls (Table 5). The between-stage differences were similar in boys with Class I and Class II patterns. The mandibular length was greater at stage CS4 than at CS2 and CS3; also, this measure was greater at stage CS5 than at CS4 (Table 4). In girls with Class I pattern, the mandibular lengths at CS4 and CS5 were greater than at CS3 and CS2. The differences between CS4 and CS5 were not significant in this group. On the other hand, the mandibular lengths at stages CS2 and CS3 in Class II girls were similar, while this measure was greater at stage CS5 than at CS4, and at CS4 it was also greater than at CS3 and CS2 (Table 5).

\section{Discussion}

In orthodontics and dentofacial orthopedics, each patient's skeletal maturation period is an important factor to be considered in order to better take advantage of his/her growth potential. In recent years, many authors have supported the efficacy of the cervical vertebrae analysis to assess skeletal age, which would represent a valid instrument to calculate the speed of growth and skeletal maturation..$^{1-12}$ Our aim in this study, was to analyze mandibular length in subjects with Class I and Class II skeletal patterns, considering their skeletal maturation stage. Sexual dimorphism in this measure was also evaluated.

The present study showed that the mandibular lengths in subjects with skeletal Class II pattern can differ from those with skeletal Class I pattern. These differences were found only at the initial stages of bone maturation, as observed in the male group at stages CS2 and CS3, and in the female group at stage CS3. These results are consistent with those of previous studies, and they show that dentoskeletal characteristics of Class II malocclusion are established early in development. ${ }^{15,16,18,26}$ The peak in mandibular growth seems to occur between CS3 and CS4, as previously reported..$^{27,28}$

In relation to the absence of statistical difference between Class I and Class II patterns at the later stages of development (CS4 and CS5), our results are in accordance with those of Bishara et al. ${ }^{19}$ (1997) and Bishara ${ }^{20}$ (1998),in which Class II subjects had shorter mandibles when compared with normal subjects only in the earlier stages of development. But the differences were not significant when the permanent dentition had completely 
erupted. These findings might suggest the possibility of a late "catch up" growth period occurring in Class II subjects. However, these studies were based on longitudinal growth changes related to the subjects' dentition stages, which seems not to be a reliable indicator of skeletal maturation. ${ }^{21-23}$ On the other hand, Stahl et al. ${ }^{24}$ (2008) compared the longitudinal craniofacial growth changes in untreated subjects with Class II malocclusion with those in subjects with normal occlusion from the prepubertal through the postpubertal stages of development, as defined by the cervical vertebrae maturation method. These authors found that the deficiency in mandibular growth in Class II subjects is significant not only at the growth spurt, but that it is also maintained at a postpubertal observation. Considering that our findings are based on cross-sectional data, the possibility that Class II dentoskeletal disharmony does not have a tendency to self-correct with growth should not be neglected.

Even though the present data are cross-sectional, they represent the first attempt to investigate possible gender differences of mandibular sizes in Class I and Class II subjects, within the same stage of bone maturation. Our results indicate that boys with the Class I pattern had greater mandibles than girls at stages CS2, CS4 and CS5, whereas in the Class II pattern the boys had greater mandibles than girls at stages CS2, CS3 and CS4. The similar mandibular lengths observed in Class II boys and girls at stage CS5 indicates the possibility of a "catch up" period in mandibular growth in Class II girls at this later stage (CS5) of bone maturation. This finding can also be observed when the between-stages differences in boys and girls are compared (Tables 4 and 5). Although the between-stages differences in Class I and Class II boys are very similar, a significant increase in mandibular length from stage CS4 to CS5 was observed only in the Class II girls, but not in the Class I girls. These results suggest that Class II girls can present a delay in the mandibular growth, and this information has important orthodontic clinical implications. A substantial number of treatment protocols in dentofacial orthopedics benefits from the inclusion of the period of accelerated man- dibular growth. For example, functional appliances have been shown to be more effective when used in the peak of mandibular growth rather than earlier. ${ }^{29}$ However, some authors have stated that because of the high variability in mandibular growth, orthodontists should take care to make this prediction for the individual patient. ${ }^{2}$ Therefore, the variables involved in the skeletal maturation should be known to improve the effectiveness of this biological index as an orthodontic tool in clinical practice.

Racial variations in the relationships between skeletal maturity established by different methods of evaluation were previously reported. ${ }^{10,11,25}$ These variations could be due to the predominant ethnic origin, climate, nutrition, socioeconomic level and urbanization..$^{30}$ The outcomes of the present study suggest that the gender and the type of skeletal malocclusion are also important factors to be considered in the skeletal maturity evaluation of a patient. Although most of the studies report that the peak in mandibular growth occurs between the CS3 and CS4 stages, ${ }^{27,28}$ this does not seem to be the case in Class II girls, in whom significant "delayed mandibular growth" could occur at stage CS5. This possible "catch up" growth of the mandible in Class II girls does not mean that the Class II will change to Class $\mathrm{I}$, but this finding is extremely relevant in order to avoid equivocal prediction of the peak in mandibular growth and, consequently, underestimate growth potential in these patients. Nevertheless, some limitation must be considered in this study, such as the lack of evaluation of regional growth and remodeling of the mandible. Moreover, the sample for our study did not include all types of Class II subjects who would be encountered in clinical practice, and the conclusions therefore cannot be extended to patients with different problems.

\section{Conclusions}

- Subjects with skeletal Class I and Class II patterns had different mandibular lengths at the earlier stages of bone maturation.

- A sexual dimorphism in this measure was observed at almost all stages, in exception of the CS5 stage in Class II. 


\section{References}

1. Baccetti T, Franchi L, McNamara JA Jr. An improved version of the cervical vertebral maturation (CVM) method for the assessment of mandibular growth. Angle Orthod. 2002;72(4):316-23.

2. Flores-Mir C, Burgess CA, Champney M, Jensen RJ, Pitcher MR, Major PW. Correlation of skeletal maturation stages determined by cervical vertebrae and hand-wrist evaluations. Angle Orthod. 2006;76(1):1-5.

3. Santos EC, Bertoz FA, Arantes F de M, Reis PM, de Bertoz AP. Skeletal maturation analysis by morphological evaluation of the cervical vertebrae. J Clin Pediatr Dent. 2006;30(3):26570.

4. Hassel B, Farman AG. Skeletal maturation evaluation using cervical vertebrae. Am J Orthod Dentofacial Orthop. 1995;107(1):58-6.

5. Caldas M de P, Ambrosano GM, Haiter Neto F. New formula to objectively evaluate skeletal maturation using lateral cephalometric radiographs. Braz Oral Res. 2007;21(4):330-5.

6. Mito T, Sato K, Mitani H. Predicting mandibular growth potential with cervical vertebral bone age. Am J Orthod Dentofacial Orthop. 2003;124(2):173-7.

7. Hellsing E. Cervical vertebral dimension in $8-11$ and 15 year old children. Acta Odontol Scand. 1991;49(4):207-13.

8. Franchi L, Bacetti T, McNamara JA Jr. Mandibular growth as related to cervical vertebral maturation and body height. Am J Orthod Dentofacial Orthop. 2000;118(3):335-40.

9. O'Reilly M, Yanniello G. Mandibular growth changes and maturation of cervical vertebrae. Angle Orthod. 1988;58(2):17984.

10. Garcia-Fernandez P, Torre H, Flores M, Rea J. The cervical vertebrae as maturational indicators. J Clin Orthod. 1998;32(4):221-5.

11. Roman PS, Palma JC, Oteo D, Nevado E. Skeletal maturation determined by cervical vertebrae development. Eur J Orthod. 2002;24(3):303-11.

12. Uysal T, Ramoglu SI, Basciftci FA, Sari Z. Chronologic age and skeletal maturation of the cervical vertebrae and handwrist: is there a relationship? Am J Orthod Dentofacial Orthop. 2006;130(5):622-8.

13. Grando G, Young AA, Vedovello Filho M, Vedovello SA, Ramirez-Yañez GO. Prevalence of malocclusions in a young Brazilian population. Int J Orthod Milwaukee. 2008;19(2):136.

14. McLain JB, Proffit WR. Oral health status in the United States: prevalence of malocclusion. J Dent Educ. 1985;49(6):38696.
15. Kerr WJ, Hirst D. Craniofacial characteristics of subjects with normal and postnormal occlusions - a longitudinal study. Am J Orthod Dentofacial Orthop. 1987;92(3):207-12 .

16. Baccetti T, Franchi L, McNamara JA Jr, Tollaro I. Early dentofacial features of Class II malocclusion: a longitudinal study from the deciduous through the mixed dentition. Am J Orthod Dentofacial Orthop. 1997;111(5):502-9.

17. Ngan PW, Byczek E, Scheick J. Longitudinal evaluation of growth changes in Class II division 1 subjects. Semin Orthod. 1997;3(4):222-31.

18. Varrela J. Early developmental traits in Class II malocclusion. Acta Odontol Scand. 1998;56(6):375-7.

19. Bishara SE, Jakobsen JR, Vorhies B, Bayati P. Changes in dentofacial structures in untreated Class II division 1 and normal subjects: a longitudinal study. Angle Orthod. 1997;67(1):5566.

20. Bishara SE. Mandibular changes in persons with untreated and treated Class II division 1 malocclusion. Am J Orthod Dentofacial Orthop. 1998;113(6):661-73.

21. Björk A, Helm S. Prediction of the age of maximum pubertal growth in body height. Angle Orthod. 1967;37(2):134-43.

22. Hägg U, Taranger J. Maturation indicators and the pubertal growth spurt. Am J Orthod. 1982;82(4):299-309.

23. So LLY. Skeletal maturation of the hand and wrist and its correlation with dental development. Aust Orthod J. 1997;15(1):19.

24. Stahl F, Baccetti T, Franchi L, McNamara JA Jr. Longitudinal growth changes in untreated subjects with Class II Division 1 malocclusion. Am J Orthod Dentofacial Orthop. 2008;134(1):125-37.

25. Lamparski D. Skeletal age assessment utilizing cervical vertebrae [thesis]. Pittsburgh: University of Pittsburgh; 1972.

26. Anderson DL, Popovich F. Lower cranial height vs craniofacial dimensions in Angle Class II malocclusion. Angle Orthod. 1983;53(3):253-60.

27. Franchi L, Baccetti T, McNamara JA Jr. Mandibular growth as related to cervical vertebral maturation and body height. Am J Orthod Dentofacial Orthop. 2000;118(3):335-40.

28. Gu Y, McNamara JA. Mandibular growth changes and cervical vertebral maturation. A cephalometric implant study. Angle Orthod. 2007;77(6):947-53.

29. Baccetti T, Franchi L, Toth LR, McNamara JA Jr. Treatment timing for Twin-block therapy. Am J Orthod Dentofacial Orthop. 2000;118(2):159-70.

30. Mappes MS, Harris EF, Behrents RG. An example of regional variation in the tempos of tooth mineralization and hand-wrist ossification. Am J Orthod Dentofacial Orthop. 1992;101(2):145-51. 